\title{
Estudio de sentencias de la custodia de menores tras la ruptura de la pareja. ¿Custodia versus bienestar?
}

\author{
Mónica López Viso ${ }^{1}$; Lucía Pedrosa Gil ${ }^{2}$
}

Recibido: 09/10/ 2020; Revisado: 16/10/2020; Aceptado: 25/01/2021

Resumen. La presente investigación tiene por objeto el análisis de la guarda y custodia y trata de ahondar en los aspectos sociales más significativos. A partir del caso específico de la provincia de Ourense (Galicia, España) se han abordado las principales consecuencias familiares, económicas y sociales de la ruptura de una pareja con hijas e hijos. Para ello, se ha realizado un análisis comparativo de las sentencias judiciales de la Audiencia Provincial de Ourense en un periodo de diez años. Los datos indican que las custodias se otorgan de forma mayoritaria y exclusiva a la madre. Este escenario presenta un nuevo tipo de unidad familiar, tras la ruptura de la pareja, monomarental en su mayoría, formada por una mujer sola con sus hijas e hijos que reciben unas escasas cuantías como pensión de alimentos.

Palabras clave: custodia de menores, pensión alimenticia, monomarentalidad, divorcio.

\section{[en] Study of awards for the custody of minors following separation. Custody versus wellbeing?}

Abstract. The aim of this research is to analyse guardianship and custody and to examine its more significant social aspects. The main family, economic and social consequences of couples with children separating are examined based on the specific case of the province of Ourense (Galicia, Spain). In order to do so, a comparative analysis was carried out of the court rulings issued by the Provincial High Court (Audiencia Provincial) of Ourense over a ten-year period. The data indicate that on a majority of occasions, the mother is granted sole custody. This scenario presents a new type of post-separation family unit, mostly single-mother, made up of a single woman with her children, who receive little in the way of child support.

Keywords: custody of minors; child support; single motherhood; divorce.

Sumario: Introducción. 1. Materiales y método. 2. Resultado. 3. Discusión crítica. 4. Conclusiones. 5. Referencias bibliográficas.

Cómo citar: López Viso, M.; Pedrosa Gil, L. (2021) Estudio de sentencias de la custodia de menores tras la ruptura de la pareja. ¿Custodia versus bienestar? Cuadernos de Trabajo Social, 34(2), 341-352.

\section{Introducción}

La atribución de la guarda y custodia de las y los hijos ${ }^{3}$ en el proceso de separación o divor- cio tiene una substancial relevancia, no sólo por las trascendentales consecuencias personales y legales que conlleva, sino también, como se analiza en este trabajo, por los efectos eco-

\footnotetext{
1 Universidad de Vigo; España.

E-mail: mviso@uvigo.es

2 Coordinadora de Servicio de Ayuda a Domicilio · Grupo OHL

E-mail: 1pedrosa.gil.25@gmail.com

3 En este documento se asumen las normas vigentes sobre el lenguaje no sexista. No obstante, a fin de facilitar la fluidez en la lectura, se podrá emplear, en ocasiones, el término genérico masculino o femenino.
} 
nómicos y sociales que producen las rupturas con respecto a las y los menores.

Las investigaciones y literatura académica sobre este tema son escasas y están mayoritariamente centradas en analizar lo efectivo de la legislación en función de sus objetivos y en las implicaciones psicológicas en las y los hijos. No hay apenas estudios en la producción científica española que traten de identificar la influencia de otros factores y las consecuencias que comporta. De ahí la importancia de esta investigación que incide en las consecuencias de las medidas de guarda y custodia en las nuevas familias encabezadas mayoritariamente por una madre sola cuidadora de sus hijos/as.

A partir del caso específico de la provincia de Ourense, se abordan las principales consecuencias familiares, económicas y sociales que se producen tras la ruptura de una pareja con hijas o hijos. Para ello se han consultado las sentencias judiciales de la Audiencia Provincial de Ourense recogidas a través del Consejo General del Poder Judicial en los últimos diez años, un total de 197 en las cuales se extrajeron los datos para el análisis posterior.

Antes de abordar el cuerpo del estudio, se ha realizado un acercamiento a los conceptos de patria potestad y guarda y custodia. Seguidamente, se analizan los elementos relativos a la custodia que quedarán reflejados en el convenio regulador, documento clave por la gran repercusión que conlleva, regulando no sólo las relaciones personales y familiares, sino también las económicas, como son, en su caso, el pago de las pensiones.

\section{La guarda y custodia: el convenio regulador como elemento clave en los acuerdos tras la ruptura}

Cuando una pareja pone fin a su relación, la justicia debe constatar tal separación y legislar sobre el reparto de bienes comunes que pueden ser tanto de carácter personal (las hijas y los hijos menores) como material (el patrimonio). La atribución de la guarda y custodia de las y los hijos comunes constituye una de las cuestiones centrales y más delicadas de resolver en los juicios de divorcio (López, 2008; Tejedor, 2012).

En primer lugar, es preciso dejar claro que patria potestad y guardia y custodia son dos conceptos diferentes (Ragel, 2001; Rivera, 2005; Moncó, 2010; San Segundo, 2011; Tejedor, 2012; Bernal, 2013). La patria potestad, en la mayoría de los ordenamientos jurídicos, aparece como un efecto legal y propio de la relación paterno-filial, es decir, un sistema de protección, cuidado, asistencia física, moral y educación de los hijos (Acuña, 2015). Salvo privación de la misma por motivos graves y vía judicial, se ejerce y pertenece en exclusiva a ambos progenitores.

La guarda y custodia de los hijos, aunque no existe una definición de la misma en los textos legales, implica el deber de los padres de velar por sus hijos y tenerlos en su compañía. Cuando los progenitores viven juntos, la guarda y custodia sobre los hijos menores de edad se encuentra subsumida en la patria potestad. Sin embargo, en situaciones de crisis de pareja, la guarda y custodia puede aparecer disociada de la patria potestad y se entiende como la determinación de la persona con quien van a convivir habitualmente los hijos $\mathrm{y}$, por lo tanto, quién va encargarse de los aspectos ordinarios de sus vidas (Ragel, 2001; Lázaro, 2002; Fábrega, 2010; Pinto, 2015).

Algunos países no establecen diferenciación entre patria potestad y custodia, debido a que no existe el concepto de patria potestad (denominada sole custody), de tal forma que en sus legislaciones el progenitor responsable de la custodia es el que se ocupa en exclusiva de la responsabilidad sobre los hijos y, por lo tanto, es quien tiene la potestad para tomar las decisiones sobre cualquier aspecto de su vida (Ramírez, 2004).

La mayor parte de la doctrina y literatura académica (Folberg, 1984; Pérez, 2009; Pérez-Salazar, 2009) diferencia tres modalidades de guarda y custodia que pueden ser atribuidas tras la ruptura de la pareja: la custodia exclusi$v a$, que conlleva una atribución de la custodia a uno de los progenitores y un régimen de visitas a favor del otro no custodio; la custodia repartida o alterna es la forma de custodia en la cada uno de los progenitores puede tener a los menores durante un periodo del año, ejerciendo los derechos de custodia y teniendo un régimen de visitas en el periodo restante; $\mathrm{y}$, finalmente, la custodia conjunta o compartida es la conjunción de la custodia legal o física de los hijos por ambos progenitores. En ésta, ambos progenitores disponen de la responsabilidad legal, así como la autoridad del cuidado de los hijos. En el Derecho Comparado se detecta una clara evolución en favor de la instauración en la práctica de regímenes de custodia com- 
partida (Aramburu, Chato, Martín y Pérez-Villar, 2006; Lathrop, 2008).

La trascendencia de la guarda y custodia, como sostiene Ragel (2011) radica, fundamentalmente, en que conlleva que lo más decisivo y esencial, como es el cuidado cotidiano y personal y la formación de los hijos, quedan en manos del progenitor que tiene la guarda y custodia, pudiendo conllevar otros efectos, que tienen importantes repercusiones económicas, al originar la obligación legal de alimentos, por parte del progenitor que no conviva con ellos.

Tanto en los procesos de separación, como en los de divorcio es preciso que toda la información y acuerdos queden reflejados en el convenio regulador, que se presenta ante el juez, tanto en los casos de mutuo acuerdo, como en los supuestos en que los cónyuges no se ponen de acuerdo, divorcio "contencioso", siendo el juez quien determina tales medidas o reglas. Es necesario precisar, que en los casos de parejas no casadas o de hecho, el legislador los ha querido equiparar a los matrimonios, y así en los casos de existencia de hijos comunes la extinción de esa pareja de hecho se someterá a un régimen idéntico al de un matrimonio ${ }^{4}$.

El convenio regulador deberá incluir un plan de parentalidad para determinar cómo se han de ejercer las responsabilidades parentales que de forma ineludible contenga como mínimo el cuidado de los hijos, el régimen de estancia y comunicación de los hijos con el progenitor que no convive de forma habitual con ellos, así como la asignación del uso y disfrute de la vivienda y el ajuar familiar. Se trata de un documento clave $y$, aunque en el futuro se podrá modificar si fuera necesario, sin duda marca las pautas de cómo discurrirá la relación entre las partes tras la ruptura de la pareja. En este documento se registran además el reparto económico, las pensiones alimenticias, los gastos compartidos y las pensiones compensatorias si las hubiera (Rivera, 2005). Supondrá, por tanto, un momento de especial trascendencia por la gran repercusión que conlleva, afectando no sólo a las relaciones personales y familiares, sino también a las patrimoniales (Herranz, 2014). Si bien, no existe una regulación específica, a nivel nacional, con respecto a los planes de parentalidad, las legislaciones autonómicas de Cataluña, Aragón, País Vasco y Valencia presentan una regulación propia al respecto, debiendo aportar un plan relaciones familiares tras la ruptura, cuando haya hijos menores y con independencia de que se trate de un procedimiento consensuado o controvertido.

El Trabajo Social como disciplina tiene una importante aportación en este ámbito y específicamente en lo que afecta no sólo a las labores de mediación y asesoramiento (Rondón y $\mathrm{Mu}$ nuera, 2009; Curbelo y Del Sol, 2010; Antón 2014), sino también a las situaciones de intervención del posdivorcio (Ruiz, 2010). En la práctica habitual, las y los trabajadores sociales se enfrentan fundamentalmente a supuestos de guarda y custodia en procesos judiciales, los cuáles exigen valorar de forma meticulosa todos los aspectos culturales, económicos y sociales (Simón, 2009).

Entre los factores contemplados en los planes de parentalidad, uno de los puntos más conflictivos a la hora de lograr un acuerdo suele representarlo la cuantía que se debe establecer en concepto de pensión de alimentos (Ramos, 2007). Esta pensión servirá para cubrir los gastos ordinarios de los hijos en materia de alimento, vestido, vivienda, educación y cuidados médicos. Se entiende la pensión de alimentos como una obligación, derivada de la patria potestad y, como sostiene Barrio (2017), se trata no sólo de una obligación jurídica sino de un deber moral no existiendo ningún precepto que exonere de ella.

Las pensiones alimenticias, según la investigación de Solsona y Simó (2016) realizada entre 1996 y 2002, se encuentran recogidas en el $85 \%$ de las sentencias de separación y en el $81 \%$ de las sentencias de divorcio de matrimonios con hijos menores. Según las autoras, existe una evidente diferencia de género respecto a quién corresponde abonar las pensiones alimenticias, que encuentra su explicación, por un lado, en el hecho de que las custodias de los hijos son mayoritariamente asignadas a las madres; y por el otro, en las persistentes diferencias en la situación económica y laboral de hombres y mujeres.

A diferencia de otros países europeos, no aparece en la legislación española ningún baremo obligatorio al que se debe ajustar el juez a la hora de establecer la pensión alimenticia. Si bien, en el año 2013, el Consejo General del Poder Judicial ha aprobado unas pautas orien-

De aquí en adelante el término "divorcio" o "separación” se empleará tanto para aludir a las rupturas de matrimonios legales como a las de uniones de las parejas de hecho. 
tadoras para calcular la pensión de alimentos (CGPJ, 2019), éstas carecen de carácter vinculante.

\section{La familia monomarental tras la ruptura: custodia versus bienestar}

A pesar de las transformaciones sociales y familiares, la tendencia es que los hijos, sobre todo los menores de siete años, queden bajo la custodia de la madre (Moncó, 2010). Así, el aumento del divorcio en nuestro país, al igual que ha pasado en otros países europeos, ha sido acompañado por el crecimiento acelerado de hogares encabezados por una madre sola (Avilés, 2015).

La monoparentalidad/monomarentalidad no es un hecho nuevo en la historia, pero sí lo es el reconocimiento público y la sensibilización hacia esta nueva situación familiar y las consecuencias sociales y políticas que comporta. Es, por lo tanto, un fenómeno complejo y que afecta a diversas situaciones familiares y sociales derivadas de su propio origen. Si bien, a efectos de este estudio, "se consideran familias monoparentales o monomarentales, los núcleos familiares constituidos por una sola persona adulta, ya sea hombre o mujer, y al menos una persona menor" (Perondi, 2012:38).

Es muy reciente, a principios de este siglo XXI, cuando se recategoriza a estas familias, bajo el nombre de familias monomarentales, término que a pesar de su inexactitud lingüística $^{5}$, adquiere un significado de reivindicación política, al observar que la mayoría de estas familias están representadas por una mujer sola cuidadora de sus hijos/as (Santibáñez, Flores y Martín, 2018), permitiéndonos interpretar como una entidad propia, la realidad mayoritaria de este tipo de unidad familiar. Siendo incorporado tanto por los estudios científicos como por diversos sectores sociales y asociaciones en sus respectivos discursos para referirse a la monoparentalidad femenina (Avilés, 2013).

En la Unión Europea, el 16\% de las familias están formadas con un único progenitor. De ellas, el 83,7\% están encabezadas por la madre y el 16,3\% por el padre (Eurostat, 2015). En la misma línea, los datos ofrecidos por un Informe de Save The Children (Sastre, 2015) advierten que las familias de un único progeni- tor, en su gran mayoría, están compuestas por una mujer sola a cargo de los hijos $(82 \%$ de los casos).

Paralelamente, numerosos estudios han revelado la estrecha relación entre las rupturas familiares y el deterioro económico de las familias, incidiendo en particular en las mujeres y los menores (Bartfeld, 2000; Vela, 2011). Son los procesos de ruptura matrimonial el factor que influye más en el surgimiento de las familias monomarentales (Goñi, 2005) y este esquema familiar se vincula frecuentemente con la pobreza o exclusión social, estando presente en más de la mitad de estos hogares (Santibáñez, Flores y Martin, 2017). El estudio realizado por Manting y Bouman (2006), analizando los efectos a corto y largo plazo de los divorcios en Holanda, entre 1989 y 2000, indica que el deterioro del bienestar tras el divorcio afecta en mucha mayor medida a las mujeres que a los hombres, y es la presencia o no de los niños un elemento concluyente en esta pérdida: quien tiene la custodia de los menores pierde más (Jarvis y Jenkins, 1999). Diversos trabajos confirman el alto riesgo de sufrir exclusión social de las familias monomarentales en España (Morgado, González y Jiménez, 2003). En el informe de Monoparentalidad e infancia, de 2006, se indica que la tasa de pobreza en los núcleos de familias monoparentales alcanzaba el 40,3\% (Flaquer, Almeda y Navarro, 2006).

Añadido a ello, los problemas sociales derivados de los incumplimientos de la pensión de alimentos establecidos a favor de los hijos menores de edad, han suscitado preocupación tanto a nivel estatal como internacional (Tomás, 2006). En muchos de los casos de monomarentalidad vinculada a la separación matrimonial, no se derivan ingresos propios, o bien se percibe una pensión que no garantiza la autosuficiencia económica de la familia, de manera que el impago de las pensiones, puede desembocar fácilmente en procesos de pobreza y la exclusión (Goñi, 2005). La literatura sobre la situación del posdivorcio indica alto niveles de incumplimiento en la pensión de manutención (Bucheli y Vigorito, 2015; Morgado, González y Jiménez, 2003). Las diversas razones del impago de la pensión desde una perspectiva jurídica, se vinculan para algunos autores, con la fijación de las cuantías, la falta de conocimien-

La Real Academia de la Lengua (RAE) no recoge este concepto; si bien es cada vez de uso más frecuente en las investigaciones y análisis para denominar a las familias mayoritariamente encabezadas por una mujer. 
to de la situación económica del demandado y los lentos procedimientos y medidas para obligar a pagar la pensión demandada (Vega y Smith, 2009). Siguiendo a Mandel (1995), se considera que al tratar con las familias separadas en las que no se paga la manutención, los abogados, trabajadores sociales y jueces a menudo no saben cómo pueden intervenir con éxito (Morgado, González y Jiménez 2003).

Las nuevas formas de familia exigen respuestas sociales y una intervención social orientada al cambio de pautas en el asesoramiento, la comunicación y la resolución de conflictos (Smale, Tuson y Statham, 2003; Cuberlo y del Sol, 2010), así como un conocimiento del entorno y de los nuevos escenarios que implica el posdivorcio, que permitan mejorar las futuras actuaciones profesionales.

\section{Materiales y método}

Nuestro estudio aborda un análisis de las sentencias judiciales, un total de 197, dictadas por los Jugados de Primera Instancia y modificadas por la Audiencia Provincial de Ourense, desde el mes de marzo de 2008 hasta el mes de abril de 2018. Estas sentencias de la Audiencia Provincial de Ourense resuelven los recursos de apelación frente a sentencias de los Juzgados de Familia en procesos de separación, divorcio o medidas paterno-filiales y modificación de medidas, que se pronuncian sobre guarda y custodia.

Se utilizó la base de datos jurisprudencial del Centro de Documentación Judicial (CENDOJ), de acceso público. Se realizaron búsquedas centradas en las sentencias dictadas por la Audiencia Provincial de Ourense a través de las siguientes palabras clave: jurisdicción: civil; tipo de procedimiento: sentencia de separación o divorcio; tipo de órgano: Audiencia Provincial; localización: Ourense. Los resultados obtenidos se limitaron con el término "guarda y custodia"). A raíz de esta búsqueda se obtuvo un resultado inicial de 237 sentencias. Una vez consultadas todas ellas, se descartaron 40, al no tener relación con la investigación estudiada, obteniéndose un total válido de 197 sentencias. A partir de estas sentencias, se ha realizado un volcado y sistematización de la información, elaborando una base de datos por cada año para su posterior análisis.

Se trata de un estudio ex post retrospectivo comparativo de tipo exploratorio. En una pri- mera fase, se realizó un análisis previo de sentencias para identificar los siguientes factores: el tipo de procedimiento de la sentencia: divorcio o separación; el sentido de las decisiones adoptadas sobre la atribución de la guarda y custodia de los hijos e hijas: exclusiva madre, exclusiva padre, compartida u otorgada a la administración; el número de hijos objeto de la sentencia; las cuantías de la pensión de alimentos y de la pensión compensatoria; y el régimen de visitas, es decir, la decisión sobre los tiempos, condiciones y contextos en los que se produce la relación del niño o niña con el progenitor no custodio. A partir de ello, se utilizó un protocolo confeccionado ad hoc teniendo en consideración variables genéricas (número de sentencias, número hijos e hijas, tipo de procedimiento); variables económicas (pensión de alimentos, pensión compensatoria); variables referentes a la guarda y custodia (custodia exclusiva o compartida, régimen de visitas).

Se analizaron todos los datos a nivel descriptivo y comparativo, mediante el paquete estadístico SPSS versión 19. Las pruebas estadísticas realizadas para la comprobación de datos descriptivos fueron tablas de contingencia.

\section{Resultados}

El divorcio o la separación de la pareja es un fenómeno complejo en el que toman parte un buen número de variables de diferente naturale$\mathrm{za}$, y que puede verse como una crisis que implica necesariamente cambios en cada uno de los integrantes del sistema. En la provincia de Ourense el estudio de las sentencias de rupturas de pareja, mayoritariamente divorcios, en los últimos diez años, revelaron que la custodia de los hijos e hijas menores se sigue otorgando, de forma mayoritaria, a las mujeres, representando las custodias compartidas y las exclusivas al padre, porcentajes muy inferiores. Como lógico resultado, en la gran mayoría de las sentencias el pago de la pensión de alimentos fue asignado al padre, como progenitor no custodio.

El número de sentencias analizadas que fueron dicatadas en la Audiencia Provincial de Ourense a lo largo de diez años fueron un total de 197. Los años que más sentencias se dictaron en relación con los autos de juicio de divorcio o separación procedentes del Juzgado de Primera Instancia han sido el 2016 y 2018, 
seguido del año 2014 con un total de 27 sentencias. Siendo la media de sentencias dictadas por año de 17,7 .

El tipo de procedimiento de la sentencia ha sido el de divorcio, contencioso o de mutuo acuerdo, con un total de un $87,3 \%$, mientras que el de separación, matrimonial y no matrimonial, tan sólo es un 12,6\%.

En relación con las familias y el número de menores que se han visto afectados a lo largo de estos diez años (Tabla 1) se puede afirmar que la mayoría de los casos, concretamente el $70,5 \%$ (139 casos), se correspondieron con parejas con un solo hijo/a, el 25,8\% (51 casos del total) tenían dos hijos/as y poco más del 3,5\% ( 7 casos) afectaron a parejas con tres hijos/as. Ninguna de las sentencias recogidas durante este período se corresponde con familias con más tres hijos/as.

Tabla 1. Tamaño muestral en porcentajes, según el número de hijos/as: años 2008 al 2018

\begin{tabular}{cccc}
\hline N. $^{\circ}$ de Hijos/as & 1 & 2 & 3 \\
\hline Total & 139 & 51 & 7 \\
Porcentaje (\%) & 70,56 & 25,89 & 3,55 \\
\hline
\end{tabular}

Fuente: Elaboración propia, 2019

En la gran mayoría de las sentencias la atribución de la custodia se otorgó de manera exclusiva para la madre, en el $70,7 \%$ de los casos (Tabla 2), seguida de la custodia compartida, con el
$16,1 \%$, y la custodia exclusiva para el padre fue apenas del 12,6\%; siendo excepcional, un caso en el año 2014, en la que la custodia se ha otorgado a la administración pública temporalmente.

Tabla 2. Tipo de custodias otorgadas en la provincia de Ourense: años 2008 al 2018

\begin{tabular}{ccccc}
\hline & Exclusiva madre & Exclusiva padre & Compartida & Administración \\
\hline Total & 140 & 25 & 32 & 1 \\
Porcentaje $(\%)$ & 70.71 & 12,63 & 16,16 & 0,50 \\
\hline
\end{tabular}

Fuente: Elaboración propia, 2019

En la evolución de las custodias otorgadas a lo largo de los últimos diez años en la Audiencia Provincial de Ourense (Figura 1), se observa que, mayoritariamente, la custodia ha sido otorgada a la madre, destacando los años 2014 (20) y 2016 (19), con una media de 18,9 casos por año. Con una clara menor presencia está la custodia compartida, con una media de cuatro custodias anuales, si bien se ha ido in- crementando a lo largo del periodo estudiado, pasando de una media de dos custodias compartidas otorgadas entre el año 2008 al 2011, a cinco custodias anuales entre 2012 y 2018 . En tercer lugar, la custodia exclusiva para el padre, a pesar, como se ha visto, de su escasa representación sobre el total $(12,7 \%)$, ha ido incrementándose en los últimos años.

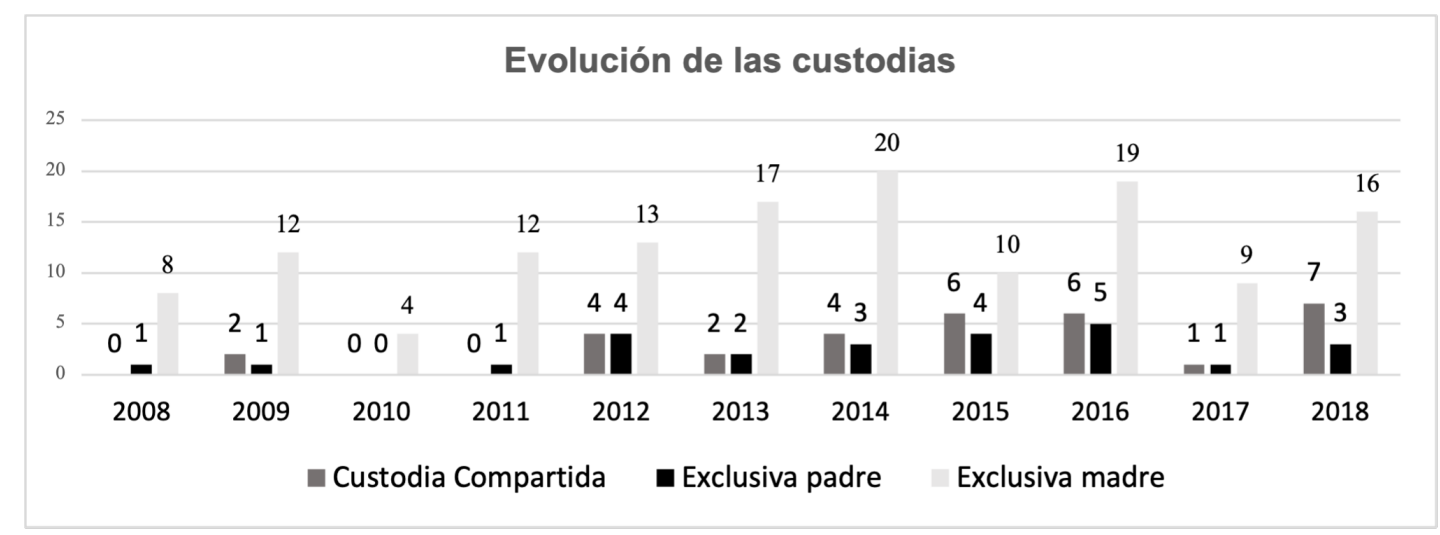

Figura 1: Evolución de las custodias. Elaboración propia, 2019 
Con respecto a los dos principales tipos de pensiones contempladas en los convenios reguladores, la pensión de alimentos y la pensión compensatoria, los resultados son una consecuencia lógica de la atribución de las custodias, al constituirse como deberes impuestos a uno de los progenitores, el progenitor no custodio, generalmente de forma mensual. En el caso de la pensión de alimentos, ha estado presente en el $83,7 \%$ de las sentencias analizadas (165 de 197), siendo mayoritariamente asignada, el 71,7\% (165), al padre como progenitor no custodio. Correspondiendo sólo en el 12,63\% de los casos (29) la obligación del pago a la madre. El resto correspondió a casos de custodia compartida.
Respecto a las cuantías de la pensión de alimentos que es otorgada al padre o madre no custodio, se aprecian unos resultados que tienen una especial relevancia. En la mayoría de las sentencias recogidas, el $60,2 \%$, se fijó una pensión de alimentos por cada menor, de entre 100 y 300 euros. De éstas, en el 28,9\% de los casos se trató de pensiones entre 100 y 199 euros y en el $31,2 \%$, entre 200 y 299 euros. Los datos revelaron que menos del veinte por ciento de los casos, apenas en el 18,7\% de las sentencias, la pensión de alimentos se encuentra entre 300 y 399 euros y que por encima de los 400 se situó sólo el $12,5 \%$ de los casos y escasamente el $5,1 \%$, superó los 500 euros.

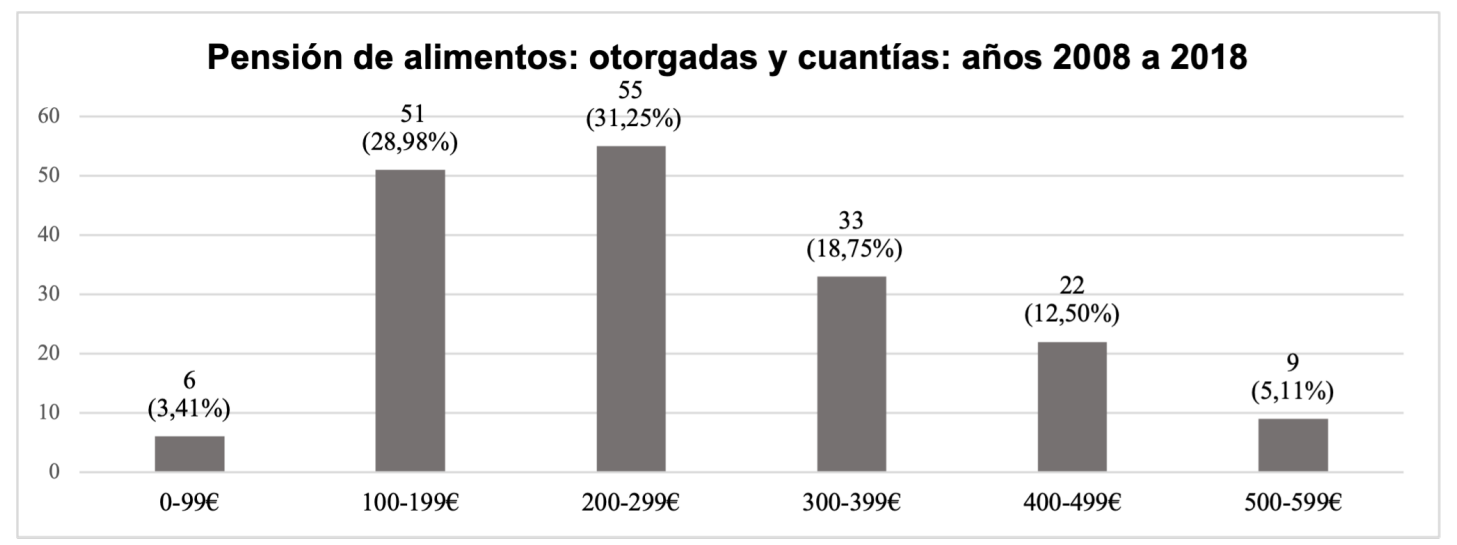

Figura 2: Pensión de alimentos. Elaboración propia, 2019

Cabe señalar que, en lo que se refiere a la pensión compensatoria, tal y como se contempla en la Tabla 3, de las 197 sentencias observadas a lo largo de estos últimos diez años, tan sólo se han determinado en doce casos. En esta modalidad de pensión, el intervalo entre 100 y 399 euros ha sido el más destacado con un total de 10 casos, seguido de dos casos entre 400 y 599 euros.

Tabla 3. Tamaño muestral en total y porcentajes de la pensión compensatoria: años 2008 al 2018

\begin{tabular}{cccccc}
\hline $\begin{array}{l}\text { Pensión com- } \\
\text { pensatoria }(€)\end{array}$ & $100-199$ & $200-299$ & $300-399$ & $400-499$ & $500-599$ \\
\hline Total & 5 & 2 & 3 & 1 & 1 \\
Porcentaje $(\%)$ & 41,67 & 16,67 & 25 & 8,33 & 8,33 \\
\hline
\end{tabular}

Fuente: Elaboración propia, 2019

En todo convenio regulador otro de los elementos imprescindibles es el llamado régimen de visitas que se le otorga al progenitor no custodio. En primer lugar, en casi el $40 \%$ de las sentencias analizadas se fijaron los fines de semana alternos, como principal periodo de tiempo que el progenitor no custodio tiene a sus hijos/as, un total de 116 casos, es decir, el $39,6 \%$. Generalmente, suele ser desde la salida del colegio del viernes al domingo por la tarde. Si bien, también se asignaron las visitas durante la semana, los martes $(13,6 \%)$ y los jueves $(14,7 \%)$, con mayor frecuencia, y los viernes y los lunes, con menores asignaciones (el 4,4\% y 
$4,8 \%$, respectivamente). Finalmente, en el 11,3 $\%$ de los casos (33), el régimen de visitas se realizó en el Punto de Encuentro, espacio neutral para favorecer el encuentro del niño con sus progenitores no custodios, en situaciones de conflicto, al que se accede, generalmente por decisión judicial o derivación de servicios sociales.

\section{Discusión crítica}

La ruptura de una pareja con hijos e hijas menores puede ser entendida como un proceso de transición en la vida personal que conllevará cambios en la familia, con efectos en las dinámicas, economía y los roles de todos los miembros.

En relación con las familias y el número de menores que se han visto afectados por los casos de divorcio y separación en la provincia de Ourense, la mayoría de las parejas tienen una sola hija o hijo y ninguna de las sentencias objeto del estudio afecta a familias con más de tres menores. Estos resultados están en consonancia con los datos de la Encuesta Continua de Hogares (ECH) del año 2018 del Instituto Nacional de Estadística (INE) y se explican al ser Ourense la segunda provincia de España con menor tasa de natalidad, duplicando la media nacional de número de hogares formados por parejas sin hijos/as. Por otro lado, algunos investigadores señalan que los primeros años de matrimonio, cuando las y los hijos están en edad escolar, son los más difíciles de sobrellevar y es cuando se produce un incremento del número de divorcios (Eguiluz, 2016), aunque no se dispone de evidencias en nuestro estudio en este sentido.

Una de las cuestiones centrales del proceso de ruptura de la pareja es la atribución de la custodia de las y los hijos menores. Los datos nos indican que, en las 197 sentencias analizadas y que fueron dictadas por la Audiencia Provincial de Ourense a lo largo de diez años, la atribución de la custodia sigue otorgándose de forma mayoritaria a la madre. Los resultados obtenidos en nuestra investigación coinciden, con algunas variaciones, con los datos del INE (2018) referidos a las sentencias de rupturas matrimoniales en primera instancia en la provincia de Ourense, ejerciendo la custodia la madre en casi el $70 \%$ y mostrando la custodia compartida una evolución creciente desde 2008 hasta 2018, en consonancia con la media de Galicia. A nivel autonómico en este periodo, la custodia ejercida por la madre ha presentado, en la misma línea, una tendencia decreciente entre 2008 y 2018, en favor de la custodia compartida, mostrando apenas variación la custodia ejercida por el padre.

En relación con la asignación de la custodia compartida, se observa similitud con las tendencias contempladas en los estudios realizados por Lathrop (2008), Aramburu, Chato, Martín y Pérez-Villar (2006).

Confirmando lo señalado y consecuencia de ello, los informes de Save the children (2015) y los datos de Eurostat (2015) revelan que la inmensa mayoría de las familias monoparentales están formadas por una mujer sola con sus hijos, lo que hace pertinente utilizar el término de monomarentalidad. La acepción de monomarentalidad nos permite revelar que una entidad propia, la realidad mayoritaria de este tipo de unidad familiar (Sastre, 2015; Santibañez, Flores y Martín, 2018) surge principalmente de los procesos de ruptura matrimonial, al ser éste, como señala Goñi, el factor que más incide en la aparición de estas familias (2005). Se trata, por lo tanto, de apropiarse de las palabras para visibilizar realidades y resignificar el concepto con "marentalidad".

Se deduce que la persistente diferencia de género en la distribución de los roles se sigue manteniendo como referente a la hora de conceder las custodias a favor de las madres. La atribución de las custodias a los padres ha sido otorgada de forma excepcional. Esta resistencia de los estereotipos responde a una estructura familiarista en la que se encuadra nuestro país, y que no desaparece con la ruptura de la pareja. No parece, por lo tanto, que pueda imponerse un ejercicio de corresponsabilidad parental cuando se produce la ruptura de pareja, si dicha igualdad y corresponsabilidad no se exige ni se protege durante la convivencia (Moraga, 2014).

En lo que se refiere a las pensiones alimenticias a las hijas e hijos menores, en sintonía con los datos expresados por diversos estudios, están presentes en la mayoría de las sentencias analizadas (en 165 de las 197). En consecuencia lógica de la atribución de las custodias, corresponde sufragarlas al padre como progenitor no custodio. Como era predecible, y en consonancia con Solsona y Simó (2016) la diferencia de género es de nuevo aquí relevante y consecuencia directa de la atribución de las custodias. 
Finalmente, en relación con las cuantías de la pensión de alimentos se manifiestan unos resultados que tienen una especial relevancia, al constatar que en más de la mitad de las sentencias se establece una pensión de alimentos entre 100 y 300 euros y que por encima de los 400 euros sólo se sitúan el $16 \%$ de los casos. En este sentido, es curioso que el Código Civil afirme que su cuantía deberá establecerse de acuerdo a las necesidades del favorecido por dicha pensión. Siendo competencia exclusiva del libre y prudente arbitrio judicial la determinación de su cuantía, quedando difuminada en el margen de cobertura de las necesidades mínimas de los menores (Bonell, 2016).

Aunque no se han encontrado estudios que permitan discutir los datos presentados, sí existen investigaciones que exponen la estrecha relación registrada entre los procesos de ruptura y la pérdida de bienestar económico del núcleo familiar -incidiendo de forma particular en las mujeres y los hijos (Jarvis y Jenkins, 1999,Bartfeld, 2000; Vela, 2011)- y el alto riesgo de exclusión social y pobreza de las familias monomarentales en España (Morgado, González y Jiménez, 2003; Goñi, 2005; Flaquer, Almeda y Navarro, 2006). Las circunstancias de clara exclusión en la que se hallan muchas de estas familias implican directamente a los profesionales del Trabajo Social.

\section{Conclusiones}

Bajo estas premisas se puede afirmar que las consecuencias de la guarda y custodia de las hijas e hijos menores tras la ruptura de la pareja nos plantean un panorama complejo y lleno de interrogantes, si bien nos permiten apuntar las siguientes conclusiones.

En primer lugar, el análisis de la evolución de las custodias otorgadas a lo largo de estos últimos diez años en la Audiencia Provincial de Ourense revela una evidente diferencia de género y refuerza las diferentes percepciones de los roles masculinos y femeninos, dado que las custodias son otorgadas de forma mayoritaria en exclusiva a la madre, el $70 \%$, frente al $12,6 \%$ de las ejercidas por el padre y el $16,1 \%$ la custodia compartida.

Este escenario, nos legitima a utilizar el concepto de monomarentalidad al referirnos al nuevo tipo de unidad familiar, de resultas de la ruptura, formada mayoritariamente por una mujer sola con sus hijas e hijos.
Por otro lado, la evolución creciente de la custodia compartida supone un avance hacia la corresponsabilidad parental. Si bien, esta actuación requiere políticas y cambios sociales que rompan con el desigual reparto de responsabilidades entre mujeres y hombres, no solo cuando se produce la ruptura, sino de una forma previa e integral en las relaciones de pareja.

El convenio regulador es el documento clave que contiene los términos que van a regir tras la separación o el divorcio. El contenido mínimo del mismo conlleva cómo se han de ejercer las responsabilidades parentales, registrando todo lo relativo a la estancia y comunicación con los hijos y al reparto económico, las pensiones alimenticias, los gastos compartidos y las pensiones compensatorias si las hubiera. Elementos que tendrán una enorme trascendencia, afectando no sólo a las relaciones personales y familiares, sino también a las patrimoniales y en consecuencia al bienestar social de la familia.

Un aspecto importante que revela este estudio tiene que ver con las cuantías de la pensión de alimentos que, como se observa, son otorgadas mayoritariamente al padre en calidad de progenitor no custodio. En un alto porcentaje de los casos analizados se percibe una pensión que no garantiza la autosuficiencia económica de la familia, más del 60 por ciento de los casos no superan los 300 euros y de ellas, casi la mitad no alcanzaban los 200. La ruptura de la pareja podría generar serias dificultades económicas del progenitor que asume la custodia, y por lo tanto poner en peligro el bien supremo al que debe atenderse, cual es la protección del menor.

El cuidado de los menores tras la ruptura de pareja no solo recrea las desigualdades de género, sino que cuestiona un sistema jurídico-político que niega la responsabilidad social en la sostenibilidad de la vida y cuyo mantenimiento conlleva la exclusión social de múltiples familias.

La determinación de las cuantías, que es en nuestro país competencia exclusiva del arbitrio judicial, resulta en la práctica de nuestra provincia muy alejada de la cobertura de las necesidades mínimas de las y los menores. La pensión de alimentos atiende a las necesidades humanas más básicas y garantizarla de forma justa y vinculante no es sólo una obligación jurídica sino un deber moral. Un objetivo compartido por los escasos estudios que han investigado este tema, nos permite plan- 
tear una futura línea de investigación hacia la elaboración, al igual que existe en otros países europeos, de una fórmula vinculante, y no sólo como un baremo orientativo, que sirva de guía en la fijación del valor de una pensión adecuada y que responda a criterios justos y universales.

Finalmente, puesto que la ruptura de pareja es un evento cada vez más frecuente en nuestro país, con las consecuentes circunstancias de exclusión en la que se hallan muchas de las nuevas familias, y que involucra directamente a los profesionales del Trabajo Social, se considera necesario profundizar en sus implicaciones y continuar fomentando la producción científica en este ámbito. Analizar y asesorar a la justicia y a los profesionales involucrados acerca de las consecuencias de las medidas implementadas y de la importancia de los factores sociales en el desarrollo del bienestar social de las nuevas familias, es una importante aportación de las investigaciones sociales a la justicia.

\section{Referencias bibliográficas}

Acuña San Martín, M. (2015). Cambios en la patria potestad y en especial de su ejercicio conjunto. Revista de Derecho (Valdivia), 28(1), 55-77.

Antón, Y. (2014). Trabajo Social en los Juzgados de Familia. Trabajo Social Hoy, (71), 97-114.

Aramburu, I., Chato, M., Martín, B. y Pérez-Villar, R. (2006). Estudio de Derecho Comparado sobre la regulación de la Custodia Compartida. Asociación Mujeres Juristas Themis. Recuperado de: http:// xurl.es/rse36.

Avilés Hernández, M. (2013). Origen del concepto de «monoparentalidad». Un ejercicio de contextualización sociohistórica. Papers: Revista de Sociología, 98(2), 263-285.

Avilés Hernández, M. (2015). Monoparentalidad y ruptura conyugal: implicaciones de los cambios normativos en materia de custodia (pp. 345-358). En: R. Cavallotti y C. León (ed.), Actas de la II Conference Family and Society. Barcelona: IESF.

Barrio Gallardo, A. (2017). Pensiones de alimentos y convenio regulador. InDret, (3), 1-39.

Bartfeld, J. (2000). Child Support and the Postdivorce Economic Well-Being of Mothers, Fathers, and Children. Demography, (37), 203-13. doi: 10.2307/2648122

Bernal, T. (2013). La mediación. Una solución a los conflictos de ruptura de pareja. Madrid, España: Colex.

Bonell Colmenero, R. (2016). ¿El matrimonio habrá desaparecido en 100 años? Matrimonio, Divorcio, Rematrimonio. Anuario jurídico y económico escurialense, (49), 113-136. Recuperado de: https://dialnet. unirioja.es/descarga/articulo/5461250.pdf

Bucheli, M. y Vigorito, A. (2015). Después de la ruptura: efectos de la separación en los contactos entre padres e hijos y en el bienestar de las mujeres. En: M. Bucheli, W. Cabella, M. Nathan, P. Fitermann, A. Vigorito y M. Zerpa, Cambio familiar y bienestar de las mujeres y los niños en Montevideo y Área Metropolitana. Una perspectiva longitudinal (pp. 43-63). Montevideo: Unicef.

Curbelo-Hernández, E. y Del Sol, H. (2010). Trabajo social y mediación familiar: un enfoque para la protección del menor en el proceso mediador. Orientaciones para la práctica profesional en los supuestos de ruptura de pareja. Portularia, 10(2), 33-49. doi: 10.5218/PRTS.2010.0015

Eguiluz Romo, L.L. (2016). Las mujeres y el divorcio. Una visión de género. Temas de mujeres, 1(1), 5-15. Recuperado de: http://filo.unt.edu.ar/wp-content/uploads/2015/11/t1_eguiluz_las_mujeres.pdf

Eurostat. (2015). People in the EU: who are we and how do we live? Luxembourg: Publications Office of the European Union. Recuperado de: ec.europa.eu/eurostat/documents/3217494/7089681/KS-04-15567-Es-N.pdf/8b2459fe-0e4e-4bb7-bca7-7522999c3bfd

Fábrega Ruiz, C. F. (2010). Mediación familiar y ejercicio de la patria potestad. Diario La Ley, (7443), $1-14$.

Flaquer, L., Almeda, E. y Navarro, L. (2006). Monoparentalidad e infancia. Barcelona: Fundación" La Caixa".

Folberg, J. (1984). Joint Custody and Shared Parenting. Washington D.C.: The Bureau of National Affairs and Association of Family Conciliation Courts.

Goñi Sein, J.L. (2005). La familia monoparental: ausencia de atención política y legislativa y su impacto sobre la situación sociolaboral de la mujer. Temas laborales: Revista andaluza de trabajo y bienestar social, (82), 11-46. Recuperado de: https://dialnet.unirioja.es/descarga/articulo/1395100.pdf 
Herranz González, A. (2014). Revisión jurisprudencial de la guarda y custodia compartida e interés del menor: novedades en torno a la futura ley de corresponsabilidad parental. Revista de Derecho de la UNED (RDUNED), (14), 295-324.

Jarvis, S. y Jenkins, S. P. (1999). Marital splits and income changes: Evidence from the British Household Panel Survey. Population Studies, 53(2), 237-254.

Instituto Nacional de Estadística. (2018). Nulidades, separaciones y divorcios por provincias. Recuperado de: http://www.ine.es/jaxiT3/Datos.htm?t=20173

Lathrop, F. (2008). Algunas consideraciones en torno a la custodia compartida de los hijos. Revista Chilena de Derecho Privado, (10). Recuperado de: https://dialnet.unirioja.es/servlet/articulo? codigo $=3267400$

Lázaro González, I. (2020) (Coord.) Los menores en el Derecho Español-Práctica Jurídica. Madrid: Tecnos.

López Ordiales, J.J. (2008). Custodia compartida. Cuestiones procesales. En A.M. Saravia González (Coord.). La jurisdicción de familia: especialización. Ejecución de resoluciones y custodia (pp. 249312). Madrid: Consejo General del Poder Judicial, Escuela Judicial, Cuadernos de Derecho Judicial ${ }^{\circ}$ 147.

Mandell, D. (1995). Fathers who don't pay child support: Hearing their voices. Journal of Divorce \& Remarriage, 23(1-2), 85-116.

Manting, D. y Bouman, A.M. (2006). Short-and long-term economic consequences of the dissolution of marital and consensual unions. The example of the Netherlands. European Sociological Review, 22 (4), 413-429. Recuperado de: https://www.jstor.org/stable/3806512

Moncó, B. (2010). Códigos de interpretación de los acuerdos económicos del divorcio: el caso de las familias reconstituidas. Portularia, 2(X), 1-8. Recuperado de: http://rabida.uhu.es/dspace/handle/10272/4309

Morgado, B., González, M.M. y Jiménez, I. (2003). Familias monoparentales: problemas, necesidades y recursos. Portularia, (3), 137-160.

Pérez Martín, A.J. (2007). Guarda o custodia conjunta o compartida. Tratado de Derecho de Familia. Aspectos sustantivos, 1. Valladolid: Lex Nova.

Pérez Salazar, M. (2009). La guarda y custodia compartida y el régimen de visitas: los puntos de encuentro familiar. En: J.J. Tapia, Custodia compartida y protección de menores (pp. 243-294). Madrid, España: Consejo General del Poder Judicial.

Perondi, A.C. (dir.) (2012). Familias formadas por una sola persona adulta con hijo(s) y/o hija(s) a su cargo: diagnóstico y propuestas. Madrid: Centro de Estudios Económicos Tomillo, S.A.

Pinto Andrade, C. (2015). La custodia compartida en la práctica judicial española: los criterios y factores para su atribución. Misión Jurídica, 8(9), 143-175.

Ragel Sánchez, L.F. (2001). La guarda y custodia de los hijos. Derecho privado y Constitución, (15), 281330. Recuperado de: https://dialnet.unirioja.es/servlet/articulo?Codigo $=229886$

Ramírez, M. (2004). Otro Divorcio es Posible: Aportaciones del Psicólogo a la normalización de los procesos de familia. Actas del I Congreso de Psicología Forense en Red. Colegio Oficial de Psicólogos. Madrid.

Ramos Escobedo, A. (2007). Convenio de divorcio, género y justicia: y la perdedora es... La ventana. Revista de estudios de género, 3(26), 167-204. Recuperado de: http://www.redalyc.org/articulo. oa? $\mathrm{id}=88432608$

Rivera Álvarez, J. M. (2005). La custodia compartida: génesis del nuevo art. 92 del Código Civil. Cuadernos de Trabajo Social, (18), 137-162. Recuperado de: https://revistas.ucm.es/index.php/CUTS/article/ view/CUTS0505110137A

Rondón, L. y Munuera, M. (2009). Mediación familiar: un espacio de intervención para trabajadores sociales. Trabajo Social, (11), 25-41. Recuperado de: https://eprints.ucm.es/11135/

Ruiz, P. (2010). El trabajador social como perito, testigo y especialista del sistema judicial español. Zaragoza: España: Editorial-Distribución Librería Especializada.

San Segundo, T. (2011). Maltrato y Separación: Repercusiones en los Hijos. En: C. Villagrasa (Coord.). Derecho de familia: procesos matrimoniales, convenio regulador, ejecución de sentencias, recursos, régimen tributario, familia y extranjería, parejas estables y otras vinculaciones personales y patrimoniales (pp. 541-582). Barcelona: Bosch.

Santibañez, R., Flores, N. y Martín, A. (2018). Familia monomarental y riesgo de exclusión social. Iqual. Revista de género e igualdad, (1), 123-144. Doi: 10.6018/iQual.307701

Sastre, A. (2015). Más solas que nunca. La pobreza infantil en familias monomarentales. País Vasco: Save the Children España. Recuperado de: www.savethechildren.es/publicaciones/mas-solas-que-nunca 
Simón, M. (2009). Aportaciones del Trabajo Social a la pericial de familia. Cuadernos de derecho judicial, (2), 175-210.

Smale, G., Tuson, G. y Statham, D. (2003). Problemas sociales y trabajo social: hacia la inclusión y el cambio social. Madrid, España: Morata.

Solsona Pairó, M. y Simó Noguera, C. (2016). Sentencias de separación y divorcio en España (1996-2006) a la luz de las relaciones de género. Anais, 1-19.

Tejedor Huert, M. (2012). El Interés de los Menores en los Procesos Contenciosos de Separación o Divorcio. Anuario de Psicología Jurídica, (22), 67-75.

Tomás Martínez, G. (2006). Los fondos de garantía de pensiones de alimentos. Aequalitas: Revista jurídica de igualdad de oportunidades entre mujeres y hombres, (18), 20-25. Recuperado de: https://dialnet. unirioja.es/servlet/articulo?codigo $=2109459$

Vega Robles, I. y Smith-Castro, V. (2009). Correlatos y predictores del cumplimiento de pago de la pensión alimentaria en padres divorciados o separados. Interamerican Journal of Psychology, 43(2). Recuperado de: http://www.redalyc.org/pdf/284/28412891020.pdf

Vela Sánchez, A.J. (2011). Las familias monoparentales: cuestiones que plantean su posible solución. En: E. Almeda y D. Di Nella (eds.), Las familias monoparentales a debate (pp. 105-124). Barcelona: Copalqui. 